\title{
ANTIMICROBIAL ACTIVITY OF EXTRACTS, ESSENTIAL OIL AND METABOLITES OBTAINED FROM TAGETES MENDOCINA
}

\author{
BEATRIZ LIMA ${ }^{1}$, MARÍA BELÉN AGÜERO ${ }^{l}$, JULIO ZYGADLO ${ }^{2}$, ALEJANDRO TAPIA ${ }^{1,5 *}$, CARLOS SOLIS ${ }^{3}$, \\ ANTONIETA ROJAS DE ARIAS ${ }^{4}$, GLORIA YALUFF ${ }^{4}$, SUSANA ZACCHINO ${ }^{3}$, GABRIELA EGLY FERESIN ${ }^{\prime}$, \\ GUILLERMO SCHMEDA-HIRSCHMANN ${ }^{5}$
}

\begin{abstract}
${ }^{1}$ Instituto de Biotecnología-Instituto de Ciencias Básicas, Universidad Nacional de San Juan, Av. Libertador General San Martín 1109 (O), CP 5400, San Juan, Argentina. ${ }^{2}$ Instituto Multidisciplinario de Biología Vegetal, Cátedra de Química Orgánica, Facultad de Ciencias Exactas, Físicas y Naturales, Universidad Nacional de Córdoba, Argentina; ${ }^{3}$ Área Farmacognosia, Facultad de Ciencias Bioquímicas y Farmacéuticas, Universidad Nacional del Rosario, Suipacha 531, CP 2000, Rosario, Argentina, ${ }^{4}$ Instituto de Investigaciones en Ciencias de la Salud, Universidad Nacional de Asunción, Rio de la Plata y La Gerenza, CP 2511, Asunción, Paraguay; ${ }^{5}$ Laboratorio de Química de Productos Naturales, Instituto de Química de Recursos Naturales, Universidad de Talca, Casilla 747, Talca, Chile.
\end{abstract}

(Received 20 June 2008 - Accepted 12 September 2008)

\begin{abstract}
Extracts from the Argentinean herb Tagetes mendocina Phil. (Asteraceae) were tested for antimicrobial activity against fungi, bacteria and protozoa. The different extracts (PE, DCM, MeOH and EtOAc) and the essential oil displayed activity mainly against dermatophytes, a group of fungi that produces skin infections. The bioassay-guided fractionation of PE, DCM and EtOAc extracts led to the isolation of eight compounds including two thiophenes, two acetophenone derivatives, dihydrorosefuran and three flavonoids. The thiophenes 5-(4-hydroxy-1-butynyl)-2,2-bithienyl (BBTOH) (1) and its acetate (BBTOAc) (2) proved to be highly active against the dermatophytes Microsporum gypseum, Trichophyton rubrum and T. mentagrophytes with MIC values of $3.12,3.12$ and $6.25 \mu \mathrm{g} / \mathrm{mL}$ for compound $\mathbf{1}$ and $25,3.12$ and $6.25 \mu \mathrm{g} / \mathrm{mL}$ for compound 2, respectively. In turn, the essential oil displayed a weak to moderate antifungal effect against $M$. gypseum with $\mathrm{MIC}=250 \mu \mathrm{g} / \mathrm{mL}$. The essential oil was examined by GC and GC-MS and 21 constituents $(97.3 \%)$ were identified. $(E) \beta$-ocimene, $(Z)$-tagetone, $(E)$-tagetone, $(Z)$-ocimenone, $\alpha$-pinene and $(E)$-ocimenone were the major components. In addition, thiophenes $\mathbf{1}$ and $\mathbf{2}$ and 2 -hydroxyacetophenone $\mathbf{3}$ showed antiprotozoal activity against Leishmania amazonensis, L. brasiliensis and L. infantum promastigotes with $100 \%$ lysis at $100 \mu \mathrm{g} / \mathrm{mL}$.
\end{abstract}

Keywords: Tagetes mendocina, antimicrobial activity, essential oil analysis, dermatophytes, Leishmania spp., thiophenes

\section{INTRODUCTION}

The genus Tagetes (Asteraceae) comprises 12 species in Argentina, ranging from the northwestern part of the country to the southwest in the province of San Juan $^{1,2}$. Some Tagetes species are used as medicinal plants, including Tagetes mendocina Phil. (Asteraceae), "Quinchiue" which is recommended in infusion as a diuretic in Argentina ${ }^{3}$. Previous work on Argentinean Tagetes spp. reported the chemotaxonomy, distribution, and free radical scavenging activities ${ }^{4,5,6}$. Some studies on the antimicrobial effect of several Argentinean Tagetes spp. has been published previously $7,8,9$

In a screening undertaken by our group, we found that the petroleum ether (PE) and dichloromethane (DCM) extracts of a T. mendocina sample collected in the San Juan province was active against dermatophytes, suggesting a great potential of the plant constituents, as antimicrobial agents. In this work the effects of extracts, metabolites and essential oil of T. mendocina against selected yeasts, hialohyphomycetes and dermatophytes as well as Gram $(+)$ and Gram (-) bacteria are reported. In addition, the effect of extracts and compounds against the protozoa Leishmania spp. is presented for first time.

\section{EXPERIMENTAL}

\section{Plant material}

The plant Tagetes mendocina Phil. (Asteraceae), vernacular name "Quinchihue" was collected in January 2005 in the Bauchaceta district, San Juan province (Argentina), with assistance of the local traditional healer Rodolfo Cabello. The plant material was identified by L. Ariza Espinar at Instituto Multidisciplinario de Biología Vegetal (IMBIV) CONICET, Universidad Nacional de Córdoba, Argentina and a voucher herbarium specimen (BT5) has been kept at the same Instituto.

Isolation and chemical characterization of essential oil

The aerial parts of T. mendocina $(500 \mathrm{~g})$ was hydrodistilled for 4 hours in a Clevenger-type apparatus resulting in essential oil yield of $0.66 \%(3.3 \mathrm{~mL}) . \delta^{25}$ : $0.942 \mu \mathrm{g} / \mathrm{mL}, n_{\mathrm{D}}^{25}: 1.499$ and $[\alpha]_{\mathrm{D}}^{25}:-2.70$ (in $\mathrm{CHCl}_{3}, \mathrm{c}=0.074$ ). The essential oil was dried over anhydrous sodium sulfate and stored at $-18^{\circ} \mathrm{C}$ in the dark for antimicrobial assays and chemical analyses.

GC analyses of essential oil were performed on a Shimadzu GC-R1A (FID) gas-chromatograph, fitted with a fused silica capillary column $(30 \mathrm{~m} \mathrm{x}$
0.25 i.d. mm; coating thickness $0.25 \mu \mathrm{m}$ film) coated with a $5 \%$ phenyl $95 \%$ dimethylpolysiloxane (non polar DB-5) phase. The GC operating conditions were as follows: Oven temperature was programmed from $40^{\circ} \mathrm{C}$ to $230^{\circ} \mathrm{C}$ at $2^{\circ} \mathrm{C} / \mathrm{min}$; injector and detector temperatures were set at $240^{\circ} \mathrm{C}$. The carrier gas was nitrogen at a constant flow of $0.9 \mathrm{~mL} / \mathrm{min}$. Identification of the components was performed by comparison of their retention index (RI) with reference to a homologous series of $n$-alkanes $\left(\mathrm{C}_{0}-\mathrm{C}_{25}\right)^{10}$ and with those of pure authentic samples. GC-MS analyses were performed with a Perkin Elmer Q-700 spectrometer equipped with an apolar fused silica capillary column coated with a phase 5\% phenyl 95\% dimethylpolysiloxane (DB-5) (30 m x 0.25 i.d. $\mathrm{mm}$; coating thickness $0.25 \mu \mathrm{m}$ film). The analytical conditions were: oven temperature from $40^{\circ} \mathrm{C}$ to $230^{\circ} \mathrm{C}$ at $2^{\circ} \mathrm{C} / \mathrm{min}$, the carrier gas was helium at a constant flow of $0.9 \mathrm{~mL} / \mathrm{min}$, the ion source was maintained at $70 \mathrm{eV}$. The oil components were identified by using two computer MS libraries (Wiley and Nist) using retention indices as a pre-selection routine, visual inspection of the mass spectra from literature for confirmation ${ }^{11}$ and co-injection with authentic compounds.

Preparation of extracts from aerial parts: A second representative sample of the air-dried plant material $(2.0 \mathrm{~kg})$ was successively extracted at room temperature $(3 \times 96 \mathrm{~h})$ with petroleum ether (PE), dichloromethane (DCM) and methanol $(\mathrm{MeOH})$. After extraction, each extract was evaporated to dryness to give semisolid residues to afford a PE, DCM and $\mathrm{MeOH}$ extracts. The w/w yields in terms of dry starting material for the PE, DCM and $\mathrm{MeOH}$ extract were $1.28 \%(22.56 \mathrm{~g}), 0.59 \%(11.86 \mathrm{~g})$ and $6.0 \%(120.17 \mathrm{~g})$ respectively.

Hydrolate EtOAc extract: The remaining hydrolate, after essential oil hydrodistilled, was extracted with ethyl acetate (EtOAc; 3 x $500 \mathrm{~mL}$ ). EtOAc phase was dried over anhydrous $\mathrm{Na}_{2} \mathrm{SO}_{4}$, filtered and taken to dryness under reduced pressure to afford $3.5 \mathrm{~g}$ of hydrolate EtOAc extract (HEtOAc) with a w/w yield of $0.7 \%$.

\section{Isolation of antimicrobial compounds}

The PE and DCM extracts and the HEtOAc, presenting antifungal activity with MICs $\leq 250 \mu \mathrm{g} / \mathrm{mL}$ against at least one microbial isolate, were further investigated for antifungal compounds.

The PE extract $(15 \mathrm{~g})$ was applied onto a column (column length $70 \mathrm{~cm}$, diameter $5 \mathrm{~cm}$ ) containing $500 \mathrm{~g}$ silica gel (0.063-0.2 mesh, Merck 60) and eluted with a gradient of PE, PE:EtOAc to EtOAc affording 130 fractions of $150 \mathrm{~mL}$ each. After TLC comparison (silica gel, PE:EtOAc 95.5:0.5), fractions 
with similar TLC patterns were combined. The following groups of fractions were obtained: H1 (475 mg), H2 (18 mg); H3 (6 mg), H4 (2409 mg); H5 (261 $\mathrm{mg})$; H6 (151 mg); H7 (81 mg); H8 (108 mg); H9 (151 mg); H10 (80 mg); H11 (65 mg); H12 (60 mg); H13 (187 mg); H14 (91 mg); H15 (847 mg); H16 (635 mg); H17 (217 mg); H18 (108 mg) and H19 (346 mg). The antifungal activity was found mainly in fractions H13, H16 and H17. After column chromatography of H13 (187 mg), $5 \mathrm{mg}$ of thiophene 2 was obtained. The pooled fractions 16-17 afforded $50 \mathrm{mg}$ of $\beta$-sitosterol, after permeation on Sephadex LH-20 (column length $26 \mathrm{~cm}$, diameter $2.5 \mathrm{~cm}$, equilibrated with $\left.\mathrm{PE}: \mathrm{CHCl}_{3}: \mathrm{MeOH} 2: 1: 1\right)$

The DCM extract $(7.5 \mathrm{~g})$ was permeated on a Sephadex LH-20 column (column length $33 \mathrm{~cm}$, diameter $5.5 \mathrm{~cm}$, equilibrated with $\mathrm{MeOH}$ ). Twenty five fractions of $35 \mathrm{~mL}$ each were obtained. After TLC comparison (silica gel, PE:EtOAc 95.5:0.5), fractions with similar TLC patterns were combined. The following groups of fractions were obtained: 1 (3 mg; fractions 1-9), $2(1 \mathrm{~g}$, fractions 10-16), 3 (0.7 g, fractions 17-21), 4 (3 mg, fractions 22-25).

Some $300 \mathrm{mg}$ of the fraction pool 3 was chromatographed on a silica gel column (0.063-0.2 mesh, Merck 60; column length $50 \mathrm{~cm}$, diameter $3.5 \mathrm{~cm})$ and eluted with a PE-PE:EtOAc gradient to obtain 432 fractions of $5 \mathrm{~mL}$ each. After TLC comparison, fractions with similar TC patterns were pooled yielding $3 \mathrm{mg}$ thiophene $1,5 \mathrm{mg}$ thiophene 2 and $15 \mathrm{mg}$ of 4-hydroxyacetophenone 4. The HEtOAc extract $(756 \mathrm{mg})$ was applied onto a silica gel $(60 \mathrm{~g})$ column (column length $55 \mathrm{~cm}$, diameter $2 \mathrm{~cm}$ ) and eluted with DCM:EtOAc to EtOAc gradient, followed by $\mathrm{MeOH}$. Two hundred fractions of $15 \mathrm{~mL}$ each were obtained. Fractions with similar TLC patterns were combined to get $45 \mathrm{mg}$ of 3 and $51 \mathrm{mg}$ of compound $\mathbf{5}$. From the $\mathrm{MeOH}$ extract, the flavonoids patuletin $\mathbf{6}$, quercetagetin 7-O- $\beta$-D-glucoside (7) and axillarin 7-O- $\beta$-D-glucoside (8) were obtained.

\section{General experimental procedures}

Melting points were determined on a Kofler hot stage apparatus (Electrothermal 9100). IR spectra were recorded on a Nicolet Nexus FT-IR instrument. Mass spectra were measured on a MAT 95XP, Thermo Finnigan operating at $70 \mathrm{eV} .{ }^{1} \mathrm{H}-\mathrm{NMR}$ spectra were recorded at $400 \mathrm{MHz}$ and ${ }^{13} \mathrm{C}-\mathrm{NMR}$ data were obtained at $100 \mathrm{MHz}$ on a Bruker spectrometer ( $\delta$ scale). TLC spots were visualized by spraying the chromatograms with $p$-anisaldehyde:acetic acid: $\mathrm{H}_{2} \mathrm{SO}_{4}: \mathrm{EtOH}(1.5: 20: 10: 170)$ and heating at $110^{\circ} \mathrm{C}$ for $1 \mathrm{~min}$. Column chromatography was performed over Merck Kieselgel 60, particle size 0.063 $0.200 \mathrm{~mm}$.

\section{Antimicrobial activity evaluation}

Microorganisms For the antimicrobial evaluation, the strains detailed below were used. Bacteria: Staphylococcus aureus methicillin-sensitive ATCC 29213, Staphylococcus aureus methicillin-resistant ATCC 43300, Escherichia coli ATCC 25922, Escherichia coli LM 1 (LM: Laboratorio de Microbiología, Facultad de Ciencias Médicas, Universidad Nacional de Cuyo, Mendoza, Argentina), Escherichia coli LM 2, Pseudomonas aeruginosa ATCC 27853, Yersinia enterocolitica PI (PI: Pasteur Institute), Salmonella enteritidis MI (MI: Malbrán Institute), and Salmonella sp. LM. Fungi: Candida albicans ATCC 10231, Candida tropicalis C 131 (C: Centro de Referencia en Micología, FCByF, UNR), Saccharomyces cerevisiae ATCC 9763, Cryptococcus neoformans ATCC 32264, Aspergillus flavus ATCC 9170, Aspergillus fumigatus ATTC 26934, Aspergillus niger ATCC 9029, Trichophyton rubrum C 110, Trichophyton mentagrophytes ATCC 9972 and Microsporum gypseum C 115. Parasites: The following protozoa from the Instituto de Investigaciones en Ciencias de la Salud, Universidad Nacional de Asunción, Paraguay, were used: Leishmania amazonensis (IFLA/BR/67/PH8), L. brasiliensis (MHOM/ BR/75/ M2903) promastigotes and L. infantum (2259).

\section{Antibacterial activity}

Mueller Hinton broth was inoculated with cultures of less than $30 \mathrm{~h}$ old and incubated at $37^{\circ} \mathrm{C}(3 \mathrm{~h})$ to prepare the inoculum, the culture was adjusted in a spectrophotometer with sterile physiological solution to give a final organism density of $0.5 \mathrm{Mc}$ Farland scale $\left(1-5 \times 10^{5} \mathrm{CFU} / \mathrm{mL}\right)^{12,13}$. The antibacterial activity was evaluated with the agar dilution method using Mueller Hinton agar medium for Gram (+) and Gram (-) bacteria. Stock solutions of the compounds/ extracts in DMSO were diluted to give serial two-fold dilutions that were added to each medium resulting in concentrations ranging from 1000 to 10 $\mu \mathrm{g} / \mathrm{mL}$. The final concentration of DMSO in the assay did not exceed $1 \%$. The antimicrobial agent Cefotaxime (Argentia Pharmaceutica) was included in the assays as positive control. The plates were incubated for $24 \mathrm{~h}$ at $37^{\circ} \mathrm{C}$ in static conditions. Minimum Inhibitory Concentration (MIC) was defined as the lowest compounds/extracts concentration showing no visible bacterial growth after incubation time. Tests were done in triplicate. Extracts and compounds with MICs $\leq 250 \mu \mathrm{g} / \mathrm{mL}$ were considered of interes ${ }^{14}$.

Antifungal activity
The MIC of each extract/compound was determined by using broth microdilution techniques in 96 wells microtiter plates as described by the Clinical and Laboratory Standards Institute (CLSI) formerly National Committee for Clinical and Laboratory Standards (NCCLS) for yeasts (M27A2) as well as for filamentous fungi (M $38 \mathrm{~A})^{15}$. MIC values were determined in RPMI-1640 medium (Sigma, St. Louis, MO, USA) buffered to a pH 7.0 with morpholinepropanesulfonic acid (MOPS) at $0.165 \mathrm{M}$

The inocula were adjusted to $1-5 \times 10^{3} \mathrm{CFU} / \mathrm{mL}$ following the guidelines of CLSI (formerly NCCLS). Microtiters trays were incubated at $35^{\circ} \mathrm{C}$ for yeasts and hialohyphomycetes and at $28-30^{\circ} \mathrm{C}$ for dermatophyte strains in a moist, dark chamber. For the assay, stock solutions were two-fold diluted with RPMI from 1000 to $0.98 \mu \mathrm{g} / \mathrm{mL}$ (final volume $=100 \mu \mathrm{L}$ ) and a final DMSO concentration $\leq 1 \%$. A volume of $100 \mu \mathrm{L}$ of inoculum suspension was added to each well with the exception of the sterility control where sterile water was added to the well instead. The time of incubation was the same of that of the control fungus growth (a well containing culture medium and fungal inoculum, but devoid of extract or compound). MIC was defined as the minimum inhibitory concentration of the extract/compound which resulted in total inhibition of the fungal visible growth. Ketoconazole, terbinafine and amphotericin B were used as positive controls. MICs $\leq 250 \mu \mathrm{g} / \mathrm{mL}$ were considered of interest ${ }^{14}$.

\section{Leishmanicidal activity}

Promastigote inhibition studies were performed on Leishmania amazonensis (IFLA/BR/67/PH8), L. brasiliensis (MHOM/BR/75/M2903) and L. infantum (2259) grown at $22^{\circ} \mathrm{C}$ in Schneider's Drosophila medium containing $20 \%$ foetal bovine serum. Promastigote cultures in the logarithmic phase were transferred at a concentration of $10^{6}$ cells $/ \mathrm{mL}$. Compounds $(1 \mathrm{mg})$ were dissolved in $40 \mu \mathrm{L}$ DMSO and added to $1 \mathrm{~mL}$ of the medium from which aliquots were drawn. $200 \mu \mathrm{L}$ from this stock solution were dissolved in 800 $\mu \mathrm{L}$ of medium. A $100 \mu \mathrm{L}$ sample of this second solution was mixed with 100 $\mu \mathrm{L}$ of parasite culture reaching a compound concentration of $100 \mu \mathrm{g} / \mathrm{mL}$ and $0.4 \%$ of DMSO. The solution was placed in microtiter plates. All assays were carried out in triplicate. The activity of the compounds was evaluated after $72 \mathrm{~h}$ by observation of a drop of each culture with a microscope and compared with control cells. Assays to assess the drug concentration required to inhibit parasite growth were performed in triplicate ${ }^{16}$. Amphotericin B and pentamidine were used as reference compounds.

\section{RESULTS AND DISCUSSION}

From the PE, DCM and EtOAc extracts, 5 compounds (Figure 1) were isolated and identified as 5-(4-hydroxy-1-butynyl)-2,2-bithienyl (BBTOH, compound 1), 5-(4-acetoxy-1-butynyl)-2,2'-bithienyl (BBTOAc, compound 2), 2-hydroxyacetophenone (3), $p$-hydroxyacetophenone (4) and dihydrorosefuran (5). The spectroscopic data of the isolated compounds is in agreement with literature ${ }^{17}$.

5-(4-Hydroxy-1-butynyl)-2,2'-bithienyl (BBTOH) (1): colorless oil. HRMS $m / z$ (rel. int.\%): 234.340 (calc. for $\mathrm{C}_{12} \mathrm{H}_{10} \mathrm{OS}_{2}: 234.017$ ).

5-(4-Acetoxy-1-butynyl)-2,2'-bithienyl (BBTOAc) (2): colorless oil. MS $m / z$ (rel. int.\%): 276 (13) $[\mathrm{M}]^{+}\left(\mathrm{C}_{14} \mathrm{H}_{12} \mathrm{O}_{2} \mathrm{~S}_{2}\right), 217$ (15), 216 (100), 203 (14), $43(21)$.

$2 \beta-(3-m e t h y l b u t-2$ - enyl) - 4 - methyl-2,5-dihydrofuran (Dihydrorosefuran) (5): colorless oil. MS $m / z$ (rel.int.\%): $152[\mathrm{M}]^{+}\left(\mathrm{C}_{10} \mathrm{H}_{16} \mathrm{O}\right)$ $(8), 137[\mathrm{M}-\mathrm{Me}]^{+}(15), 112[\mathrm{M}-\mathrm{Me}]^{+}(24), 83\left[\mathrm{M}-\mathrm{C}_{5} \mathrm{H}_{3}\right]^{+}(20), 69\left[\mathrm{C}_{5} \mathrm{H}_{0}\right]^{10}(100)$ ${ }^{1} \mathrm{H}-\mathrm{NMR}$ : $5.66 \mathrm{t}$ (8) (H-3), $5.13 \mathrm{t}$ (8) (H-4), $4.03 \mathrm{t}$ (8) (H-5), $4.21 \mathrm{dd}(\mathrm{H}-6), 2.24$ $\mathrm{m}(\mathrm{H}-7), 1.75 \mathrm{~s}(\mathrm{H}-8), 1.66 \mathrm{~s}(\mathrm{H}-9), 1.69 \mathrm{~s}(\mathrm{H}-10) .{ }^{13} \mathrm{C}-\mathrm{NMR}: 140.427 \mathrm{~s}(\mathrm{C}-1)$, $135.300 \mathrm{~s}(\mathrm{C}-2), 124.523 \mathrm{~d}(\mathrm{C}-3), 119.737 \mathrm{~d}(\mathrm{C}-4), 76.382 \mathrm{~d}(\mathrm{C}-5), 59.137 \mathrm{t}$ (C-6), 34.202 t (C-7), 25.926 q (C-8), 18.027 q (C-9), 12.218 q (C-10). [ $\left.\alpha_{D}\right]$ : $-2.2,\left(\mathrm{c}=0.09 ; \mathrm{CHCl}_{3}\right)$. 


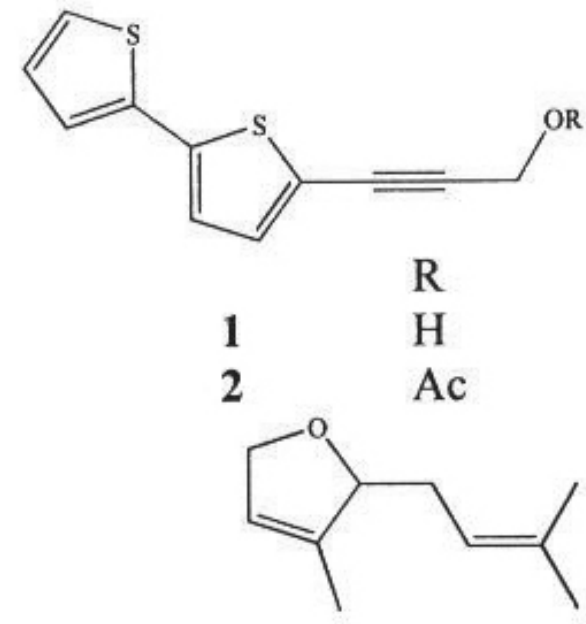

5
6<smiles>[Mg]</smiles>
$3 \mathrm{H}$ $\mathrm{R}_{1} \quad \mathrm{R}_{2}$
$4 \mathrm{OH}$
$\mathrm{OH}$<smiles>[R20]c1cc2oc(-c3ccc(O)c(O)c3)c([R2])c(=O)c2c(O)c1[R20]</smiles>

$\mathrm{R}_{1}$ $\mathrm{R}_{2}$ $\mathrm{H}$ $\mathrm{CH}_{3}$ $\mathrm{H}$ $\mathrm{H}$ $\mathrm{R}_{3}$ $\mathrm{H}$ $\mathrm{CH}_{3} \quad \mathrm{CH}_{3} \quad$ Glucose
Figure 1. Compounds isolated from Tagetes mendocina

1: 5-(4-acetoxy-1-butynyl)-2,2'-bithienyl (BBTOH); 2: 5-(4-acetoxy1-butynyl)-2,2-bithienyl (BBTOAc); 3: 2-hydroxyacetophenone; 4: 4-hydroxyacetophenone; 5: dihydrorosefuran, 6: patuletin; 7: quercetagetin 7-O- $\beta$-D-glucoside; 8: axillarin 7-O- $\beta$-D-glucoside

The thiophenes $\mathbf{1}$ and $\mathbf{2}$ were reported as constituents of Tagetes spp., while dihydrorosefuran was isolated from Artemisia pallens ${ }^{17,18}$.

The composition and quantification of thiophenes of T. minuta collected in Mendoza province (Argentine) was reported, the main thiophene identified was $\mathrm{BBTOH}^{19}$. In our T. mendocina sample, the main thiophenes were BBTOH and BBTOAc, confirming the trend observed in other species belonging to the genus.

From the $\mathrm{MeOH}$ extract, the three flavonoids 6-8, previously isolated from this species, were obtained ${ }^{6}$. The light green essential oil of $T$. mendocina was obtained in a yield of $0.6 \mathrm{~mL} / 100 \mathrm{~g}$ of fresh aerial parts. Results of the $\mathrm{GC}$ and GC-MS analysis of the essential oil are shown in Table 1, where the chemical components are listed in the order of elution of the peaks. Some 21 constituents were identified representing $97.3 \%$ of the total. The major constituents (concentrations higher than $3.5 \%$ ) were $(E) \beta$-ocimene $(28.6 \%)$, (Z)-tagetone $(28.0 \%),(E)$-tagetone $(11.7 \%),(Z)$-ocimenone $(7.4 \%), \alpha-$ pinene $(5.5 \%)$ and (E)-ocimenone $(4.7 \%)$.
Table 1. Chemical composition of Tagetes mendocina essential oil

\begin{tabular}{|c|c|c|c|}
\hline Components & $\begin{array}{c}\text { Retention } \\
\text { Index }^{\mathrm{a}}\end{array}$ & $\begin{array}{c}\text { Composition } \\
(\%)^{\mathrm{b}}\end{array}$ & $\begin{array}{c}\text { Methods of } \\
\text { identification }\end{array}$ \\
\hline$\alpha$ pinene & 939 & 5.5 & $\mathrm{Ms}_{1}$ Co \\
\hline sabinene & 975 & 3.7 & $\mathrm{Ms}_{2}$ \\
\hline$\beta$ pinene & 979 & 1.0 & $\mathrm{Ms}_{1}$ Co \\
\hline$\delta 2$ carene & 1002 & $\operatorname{tr}$ & $\mathrm{Ms}_{2}$ \\
\hline$\alpha$ terpinene & 1017 & 1.1 & $\mathrm{Ms}_{1}$ Co \\
\hline$\beta$ phellandrene & 1030 & $\operatorname{tr}$ & $\mathrm{Ms}_{2}$ \\
\hline$(Z) \beta$ ocimene & 1037 & $\operatorname{tr}$ & $\mathrm{Ms}_{2}$ \\
\hline$(E) \beta$ ocimene & 1050 & 28.6 & $\mathrm{Ms}_{1}$ Co \\
\hline dihydrotagetone & 1053 & 2.7 & $\mathrm{Ms}_{1}$ Co \\
\hline$\gamma$ terpinene & 1060 & $\operatorname{tr}$ & $\mathrm{Ms}_{2}$ \\
\hline terpinolene & 1089 & 0.5 & $\mathrm{Ms}_{2}$ \\
\hline (E)- tagetone & 1144 & 11.7 & $\mathrm{Ms}_{1}$ Co \\
\hline myrcenone & 1150 & 0.2 & $\mathrm{Ms}_{1}$ Co \\
\hline$(Z)$ - tagetone & 1152 & 28.0 & $\mathrm{Ms}_{1}$ Co \\
\hline citronellal & 1153 & $\operatorname{tr}$ & $\mathrm{Ms}_{2}$ \\
\hline isoborneol & 1162 & 1.2 & $\mathrm{Ms}_{1}$ Co \\
\hline borneol & 1169 & 0.5 & $\mathrm{Ms}_{1}$ Co \\
\hline dihydrocitronellol & 1196 & 1.8 & $\mathrm{Ms}_{2}$ \\
\hline$(Z)$ ocimenone & 1229 & 7.3 & $\mathrm{Ms}_{1}$ Co \\
\hline (E) ocimenone & 1238 & 4.7 & $\mathrm{Ms}_{1}$ Co \\
\hline geranial & 1267 & 0.1 & $\mathrm{Ms}_{1}$ Co \\
\hline
\end{tabular}

Ms: identical with those of pure reference compounds. Ms: identical with published data. Co: co injection authentic compounds; a: retention indices relative to homologous alkanes; $b$ : Percentages were calculated from the peak area without correction; tr: trace $<0.1 \%$. 
Antimicrobial activity

The antimicrobial activity of the extracts, essential oil and compounds isolated from $T$. mendocina was assessed in vitro against several yeasts, filamentous fungi, dermatophytes, Gram positive, Gram negative bacteria and protozoa. Results are showed in Table 2.

Regarding antifungal activity, the essential oil of $T$. mendocina was active against all dermatophytes assayed, being Microsporum gypseum the most susceptible species (MIC $=250 \mu \mathrm{g} / \mathrm{mL}$ ). On the other hand PE, DCM and HEtOAc extracts were active against the dermatophytes $M$. gypseum, $T$. mentagrophytes and T. rubrum. The best effect was elicited by the HEtOAc extract towards $T$. mentagrophytes with a MIC value of $125 \mu \mathrm{g} / \mathrm{mL}$ and DCM extracts with MICs $250 \mu \mathrm{g} / \mathrm{mL}$ (Table 2). None of the extracts from $T$. mendocina was active towards the yeasts $C$. albicans, $C$. tropicalis, $C$. neoformans and S. cerevisiae or the filamentous fungi A. flavus, A. fumigatus and $A$. niger with MIC values $>1000 \mu \mathrm{g} / \mathrm{mL}$ (data not shown).

From PE and DCM T. mendocina extracts, two antifungal constituents were isolated. Compound $\mathbf{1}$ showed strong activity against the dermatophytes with MICs values of 3.12, 3.12 and $6.25 \mu \mathrm{g} / \mathrm{mL}$ while for compound 2, MIC values were $25,3.12$ and $6.25 \mu \mathrm{g} / \mathrm{mL}$ towards $M$. gypseum, $T$. rubrum and $T$. mentagrophytes, respectively. The activity is considered very interesting in the case of MICs $<100 \mu \mathrm{g} / \mathrm{ml}$ for extracts and $10 \mu \mathrm{g} / \mathrm{ml}$ for isolated compounds

Thiophene 1 was previously reported as a constituent of Tagetes, Porophyllum and Echinops species, while the corresponding acetate $\mathbf{2}$ was isolated from species of the genera Berkheya, Dyssodia, Echinops and Tagetes ${ }^{21}$. The activity of thiophenes against the dermatophytes $T$. mentagrophytes and T. rubrum is of interest considering that these two fungi are responsible for approximately $80-93 \%$ of chronic and recurrent non-scalp skin infections in humans ${ }^{22} . T$. mentagrophytes and T. rubrum are the ethiological agents of tinea unguium, producer of invasive nail infections, tinea manuum (infections of palmar and interdigital areas of the hand) and tinea pedis (athlete's foot), the last one being the most prevalent fungal infection all over the world ${ }^{23} . T$. rubrum is also the most frequent ethiological agent of tinea cruris, which affect the perianal and perineal areas of adults producing highly contagious bilateral erythematous lesions ${ }^{24}$.

The antifungal effect of $T$. patula methanolic extracts against phytopathogenic fungi was enhanced after UV light exposition ${ }^{25}$. This is surely due to its thiophene constituents, which become more active after light activation. The mechanism of action of $\alpha$-terthienyl, a related thiophene, was previously reported. This compound, under UV light, promotes singlet $\mathrm{O}_{2}$ generation, which is extremely toxic for fungal membranes ${ }^{26,27,28}$.

Regarding antiprotozoal effect, the DCM extract of $T$. mendocina at $100 \mu \mathrm{g} / \mathrm{mL}$ completely lysed Leishmania amazonensis and L. brasiliensis promastigotes. The same effect was observed with the compounds $\mathbf{1 , 2}$ and $\mathbf{3}$ (Table 2).

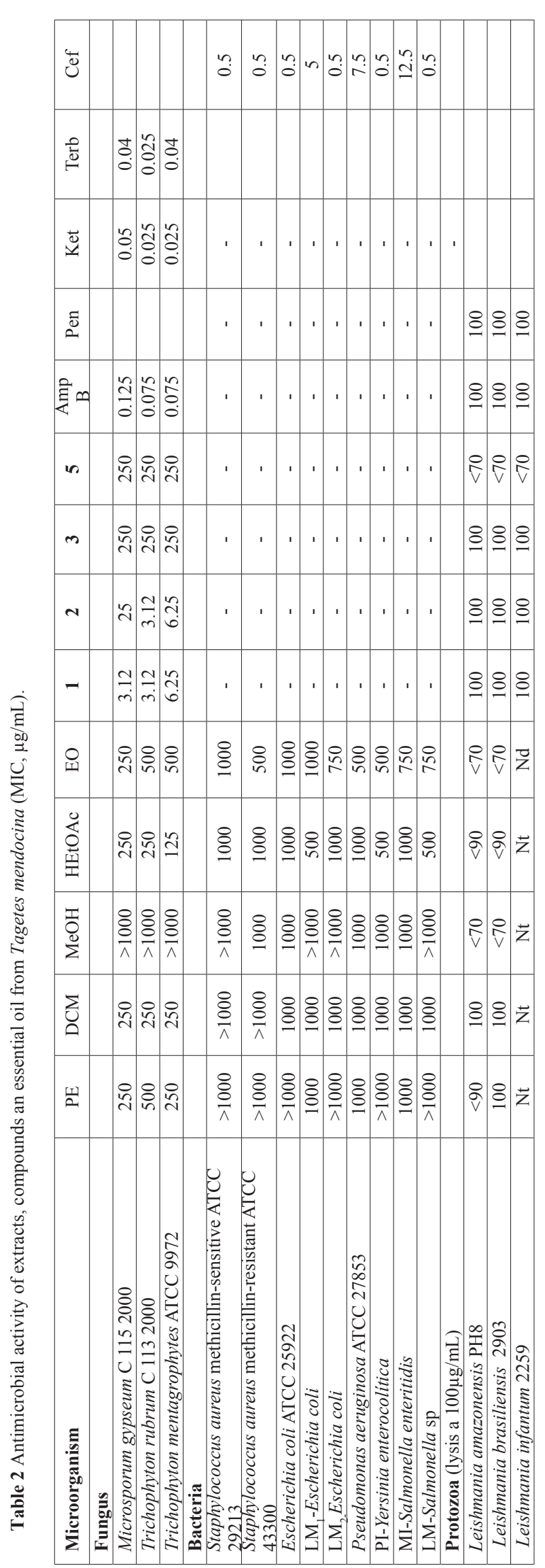

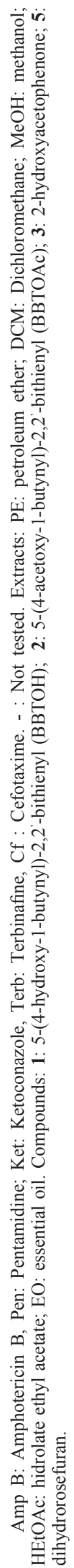


Moreover, related to antibacterial activity, the extracts $\mathrm{PE}, \mathrm{DCM}, \mathrm{MeOH}$, $\mathrm{EO}$ and HEtOAc tested, showed less activity against a panel of bacteria assayed with MIC between $500-1000 \mu \mathrm{g} / \mathrm{mL}$.

The antifungal effect, the identification of the active thiophenes BBTOH and BBTOAc as well as the chemical composition of essential oil of $T$. mendocina collected in San Juan province, Argentine are reported for the first time.

\section{ACKNOWLEDGEMENTS}

We are grateful to Universidad de Talca (Chile), Programa "Desarrollo de Productos Bioactivos", to ANPCyT Argentina (PICT R 260 and PICT 995) for financial support; to CICITCA-Universidad Nacional de San Juan, Argentina and SECyT-Universidad Nacional de Córdoba for grants to G.E.F, A.T, BL, MBA and J.A.Z. SAZ and CS are grateful to UNR (1BIO133) and CYTED (RIBIOFAR). J.A.Z. and G.E.F. are researchers from CONICET, Argentina. $\mathrm{BL}$ is grateful to CONICET for a fellowship.

\section{REFERENCES}

1. L. R. Abdala, Bol. Soc. Argent. Bot. 34, 3, (1999)

2. L. Ariza Espinar, Kurtziana 4, 51, (1967)

3. D. Bustos, A. Tapia, G. E. Feresin, L. Ariza Espinar, Fitoterapia 67, 411, (1996)

4. L. R. Abdala, P. Seeligmann, Lilloa 365, 14, (1983)

5. L. R. Abdala, M. Martinez, P. Seeligmann, Phytochemistry 30, 4037, (1991)

6. G. Schmeda-Hirschmann A. Tapia, C. Theoduloz, J. A. Rodriguez, S. Lopez, G. E. Feresin, Z. Naturforsch. 59c, 345, (2004)

7. G. E. Feresin, A. Tapia, D. Bustos, Fitoterapia 71, 429, (2000)

8. M. L. Tereschuk, M. D. Baigorí, L. R. Abdala, Fitoterapia 74, 404, (2003)

9. M. L. Tereschuk, M. D. Baigorí, L. I. De Figueroa, L. R. Abdala, Methods Mol. Biol. 268, 317, (2004)

10. A. Craveiro, F. J. A. Matos, J. W. Alencar, J. Nat. Prod. 47, 890, (1984)

11. R. P. Adams Identification of essential oil components by gas chromatography and mass spectroscopy. Allured Publ. Corp., Carol Stream, IL. USA, 1995.
12. J. H. Jorgensen, J. D. Turnidge and J. A. Washington in Manual of Clinical Microbiology $7^{\text {th }}$ ed. Antibacterial susceptibility tests: dilution and disk diffusion methods, P. R. Murray, M. A. Pfaller, F. C. Tenover, E. J. Baron, R. H. Yolken, ed., Washington, DC: ASM Press 1999; pp.1526-1543

13. National Committee for Clinical and Laboratory Standards (NCCLS). Performance standards for antimicrobial susceptibility testing; ninth informational supplement. Wayne, Pennsyslvania: NCCLS; 1999; document M100-S9, Vol. 19. No. 1, Table 2I.

14. M. Hadad, J. A. Zygadlo, B. Lima, M. Derita, G. E. Feresin S. A. Zacchino, A. Tapia, J. Chil. Chem. Soc. 52, 1886, (2007)

15. National Committee for Clinical and Laboratory Standards (NCCLS). Method M-27-A2 for yeasts, $2^{\text {nd }}$ ed, Wayne Ed.; Vol. 22 (15), pp 1-29, NCCLS, and method M-38A for filamentous fungi, $2^{\text {nd }}$ Ed., Wayne Ed.; 2002; Vol. 22 (16), 1-27.

16. B. Del Rey, A. C. Ramos, E. Caballero, A. Inchaustti, G. Yaluff, M. Medarde, A. Rojas de Arias, A. San Feliciano, Bioorg. Med. Chem. Lett 9, 2711, (1999)

17. L. Margl, A. Tei, I. Gyurjan, M. Wink, Z. Naturforsch. 57c, 63, (2002)

18. L. N. Misra, A. Chandra, R. S. Thakur, Phytochemistry 30, 549, (1991)

19. A. Gil, C. M. Ghersa, S. Perelman, Biochem. Syst. Ecol. 30, 1, (2002)

20. J. L. Ríos, M. C. Recio, J. Ethnopharm. 100, 80, (2005)

21. Dictionary of Natural Products on CDROM 2007. Chapman and Hall/ CRC, Boca Ratón, FL, U.S.A.

22. I. Weitzmann, R. Summerbell, Clin. Microbiol. Rev. 8, 240, (1995)

23. A. N. Koc, S. Silici, D. Ayangil, A. Ferahbas, S. Cankaya, Mycoses 48, $205,(2005)$

24. B. A. Insuasty, H. Torres, J. Quiroga, R. Abonía, R. Rodríguez, M. Nogueras, A. Sánchez, C. Saitz, S.L. Alvarez, A. S Zacchino, J. Chil. Chem. Soc. 51, 927 (2006).

25. D. Mares, B. Tosi, F. Poli, E. Andreotti, C. Romagnoli, Microbiol.Res. 159, 295, (2004)

26. C. Romagnoli, D. Mares, M.P. Fasulo, A. Bruni, Phytother. Res. 8, 332, (1994)

27. J. Bakker, F.J. Gommers, I. Nieuwenhuis, H. Wynberg, J. Biol. Chem. 254, 1841, (1979)

28. Nivsarkar, M., Curr. Sci. 76, 1391, (1999) 